\title{
Vólvulos y embarazo. Presentación de un caso
}

\author{
Emilio Alberto Restrepo Baena*
}

\begin{abstract}
RESUMEN: Se presenta el caso de una paciente de 26 años con un embarazo de término que consulta por dolor abdominal interpretado como trabajo de parto, y que empieza a presentar deterioro de su estado general además de sufrimiento fetal agudo. Llevada a cirugía se diagnostica vólvulo del sigmoides. Se revisa el tema.
\end{abstract}

PALABRAS CLAVES: Vólvulo, obstrucción intestinal, embarazo, muerte fetal.

SUMMARY: We show a 26 years old woman case with 39 weeks pregnancy and abdominal pain interpretated like labor; then she had compromise of her general condition and acute fetal distress. In surgery we found a Sigma Volvulus. We review subjet.

KEY WORDS: Volvulus, intestinal obstruction, pregnancy, fetal death.

\section{Resumen de la historia}

Paciente de 26 años, G 2 P 2, sin ningún antecedente importante, ingresa al servicio de urgencias obstétricas a las 39 semanas de gestación por presentar «dolores de parto». En esa misma semana presentó varios episodios de dolor abdominal difuso que interpretó como contracciones. No ha presentado vómito, y en su hábito intestinal son frecuentes los episodios de constipación.

Al examen físico se encuentra pa 120/80, T ,37.1, abdomen sin masas. Actividad uterina 3 en 10 minutos de 55 segundos. Altura uterina $32 \mathrm{cms}$. Al tacto vaginal, cuello blando, longitud $1 \mathrm{~cm}$, dilatación 3 , cefálica, estación 1 , membranas íntegras, pelvis adecuada. Se hospitaliza.

A las 6 horas, la paciente se encuentra ansiosa, álgida, pujando. 4 contracciones en 10 minutos, 4 de dilatación, se hace amniorrexis, se ordena monitoreo fetal y Demerol más Fenergan IM.

A las 8 horas se evalúa paciente agotada y muy quejumbrosa. Se hace amniotomía y se obtiene meconio II. La paciente no colabora para la realización del monitoreo. Clínicamente se auscultan bradicardias fetales. La pared abdominal se palpa tensa y muy dolorosa. Se logran apreciar 8 contracciones en un minuto. La paciente está hiperventilando, su frecuencia cardíaca es de 130 por minuto, la presión arterial de 90/60. La dilatación es de 4 $\mathrm{cm}$, sin modificaciones en el cuello. Con este cuadro clínico se hace diagnóstico de sufrimiento fetal agudo, deescordinación uterina II, descartar Abruptio Placentae. Se lleva a cesárea urgente.

En cirugía se encuentran $400 \mathrm{~cm}$ de líquido serohemático en cavidad, útero hipertónico, neonato flácido y cianótico, apgar 0/0. Ocupando la cavidad se encuentran vólvulos del

* Residente de Obstetricia y Ginecología U. de A. sigmoides sin perforación, violáceo, sin recuperación. Se decide resección de $80 \mathrm{cms}$ del colon sigmoides y colostomía tipo Hartman con piel abierta. Se instalan antibióticos.

Al niño se le hace diagnóstico de muerte por anoxia secundaria a broncoaspiración masiva.

El laboratorio muestra: creatinina $0.90 \mathrm{mgr} / \mathrm{dl}$. Hb 14.4. Hto 45 Leucocitos: 18.600. PMN: 90, Linfocitos: 9, Sedimentación 3.

Anatomía Patológica: Sigmoides. Vólvulos -Necrosis isquémica. (Ver fotografía adjunta).

Figura

EN LA FOTOGRAFIA SE OBSERVA VOLVULO DEL SIGMOIDES, CON SIGNOS DE SUFRIMIENTO POR HIPOXIA Y QUE HUBO DE SER RESECADO.

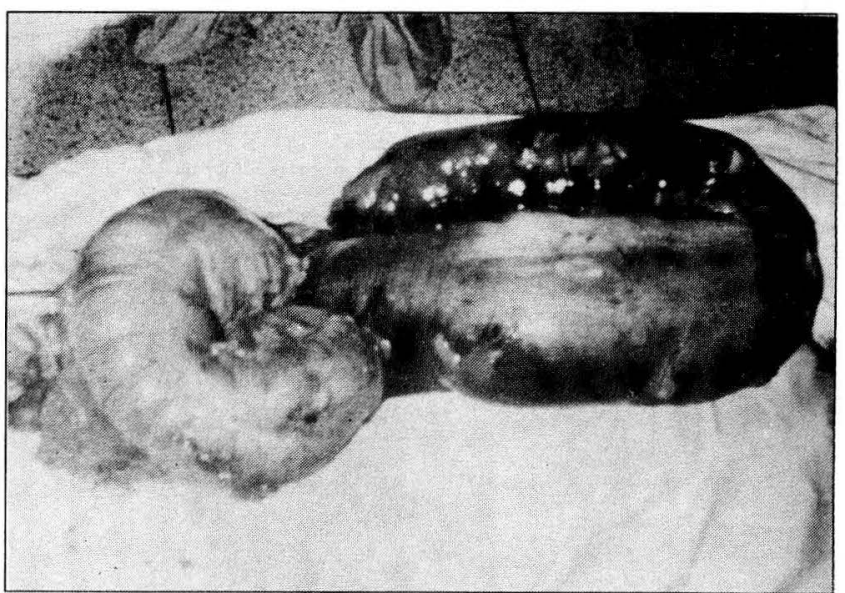

\section{Discusión}

La obstrucción intestinal complica eventualmente el embarazo, con una frecuencia que ciertamente ha venido en aumento en las últimas décadas, gracias al mayor número de laparotomías realizadas en mujeres jóvenes y su con- 
secuente aumento de síndrome adherencial. (1-2). Hoy en día es la segunda causa de cirugía abdominal no obstétrica en el embarazo luego de la apendicitis aguda. Dentro de estas causas de obstrucción, el vólvulo explica el $25 \%$ de los casos, siendo el más frecuente el de sigmoides, luego ciego, colon transverso e intestino delgado $(1,3-4,11)$.

La etiología del $60 \%$ de los casos se atribuye a las adherencias intraabdominales secundarias a cirugías previas o a procesos inflamatorios o infecciosos, y más raramente se explica por intosuscepción, hernias, neoplasia, divertículo de Meckel o idiopático del embarazo $(1,3,5,6)$. Cuando la etiología es atribuible a adherencias, hay varios momentos durante el embarazo de mayor riesgo de presentación: En el cuarto o quinto mes cuando el útero es francamente abdominal, en la etapa periparto cuando la cabeza fetal se hace intra pélvica y en el postparto cuando el tamaño del útero disminuye rápidamente (12).

Parece ser que el riesgo es mayor en el primer año y en el primer embarazo subsiguiente a la cirugía previa, y se presenta con más frecuencia durante el tercer trimestre, implicando una seria dificultad diagnóstica, por la pérdida de las relaciones anatómicas y por la superposición de síntomas que configuran una especial y compleja semiología $(1,3,4,7)$, que simula desde exageración de los cambios propios del embarazo, hasta enfermedades tan dramáticas como la Abruptio Placentae, ruptura uterina, íleo paralítico, apendicitis, colecistitis o pancreatitis que pueden presentar un cuadro completamente bizarro por la gestación; problemas ginecológicos como torsión de quistes anexiales o fibromas también pueden parecerse, lo mismo que amenaza de parto prematuro, hiperemesis tardías, enfermedad ácido péptica, cuadros sicosomáticos, etc. (1, 3-4, 7-8).

El cuadro puede ser súbito o de lenta instalación. Puede acompañarse o no de estreñimiento agudo o crónico. Suele tener dolor abdominal como síntoma principal, que puede ser difuso y episódico o volverse constante, así como tener una intensidad variable. Además de él, el vómito y el paro de fecales constituyen la triada diagnóstica clásica, aunque no siempre se presentan. Puede ser difícil diferenciar la sensibilidad abdominal de esta enfermedad con una contracción uterina, como ocurrió con la paciente del caso (1, $3-4,9-10)$.
En determinado momento de la evolución, cuando se compromete el estado general y la hidratación de la paciente, con un proceso séptico asociado, se puede presentar sufrimiento fetal agudo, compromiso serio de la salud del niño y aún muerte fetal; esto se ha descrito del 33 a 50\% de los casos (1-2). Es posible observar también manifestaciones inespecíficas como fiebre, oliguria, deshidratación, taquicardia, taquipnea, shock, sepsis, leucocitosis, etc.

Para realizar el diagnóstico se necesita un alto índice de sospecha, contando con la ayuda de la radiografía simple de abdomen, la cual no se debe dudar en ordenarla cuando el cuadro clínico sea altamente sugestivo, recordando las imágenes en J invertida, las asas escalonadas, los niveles líquidos, la dilatación «ariñonada», la pérdida de aire rectal, etc. (9).

El tratamiento definitivo de vólvulos es quirúrgico en la gran mayoría de los casos, buscando evitar llegar a estados extremos que atenten contra la vida de la madre y el niño. Se deben estabilizar los signos vitales, el equilibrio hidroelectrolítico y controlar la diuresis. Hay que usar antibióticos con espectro para Gram negativos y anaerobios, se instala una sonda nasogástrica y se procede a explorar quirúrgicamente. En lo posible, hay que monitorizar al bebé. No hay acuerdo unánime sobre la utilidad de usar sondas rectales, pero la tendencia actual es a no hacerlo. La conducta con el intestino depende de la viabilidad de éste, pudiéndose practicar desde simple liberación de adherencias con destorsión, hasta resección-anatomosis o colostomía dependiendo del compromiso $(1,3-4,9)$.

Si se determina compromiso grave del feto, debe hacerse cesárea en el mismo acto operatorio. No se recomienda el uso de tocolíticos por el peligro de alterar aún más la hemodinamia de la paciente. La vía posterior del parto se definirá según las indicaciones obstétricas del momento ( 1 , $3,5,10)$.

Más raramente se ha observado obstrucción intestinal postparto y también se describe la seudo-obstrucción del colon, llamada Síndrome de Ogilvie. Las consideraciones son las mismas que se hicieron para la paciente embarazada, pero se debe insistir hasta donde sea posible en el tratamiento médico, poniendo especial énfasis en el equilibrio hidroelectrolítico y en la desfuncionalización del intestino suspendiendo la vía oral y usando sonda nasogástrica $(1,9-10)$.

\section{BIBLIOGRAFIA}

1. Davis M., Bohon C. La obstrucción intestinal en el embarazo. En: Clin. Obstet. Ginecol. 1983; 4: 1015.

2. Kammerer WS. Non-Obstetric surgery during pregnancy. Med. Clin. North. Am. 1979; 63(6): 1157.

3. Charles D., Stronge J. Special problems of the colon and rectum encountered in obstetric practice. Clin. Obstet. Gynecol. 1972; 1: 522.

4. Schaefer G., Graber E. Complicaciones Quirúrgicas en Obstetricia. Barcelona, Salvat Editores, 1983; 488.

5. Hill LM., Symmonds RE. Small bowel obstruction in pregnancy. Obstet. Gynecol. 1977; 49(2): 170.

6. Glinter KP. Intestinal obstruction complicating pregnancy. JAMA 1973; $72: 979$.
7. Beck WW. Intestinal Obstruction in Pregnancy. Obstet Gynecol $1974 ; 43(3): 374$

8. Weston PV., Lindheimer M. Intermittent intestinal obstruction simulating hyperemesis gravidarum. Obstet. Gynecol. 1971; 37(1): 106.

9. Schwartz S. Principios de Cirugía. 5a ed. Editorial Interamericana, México, 1991; 1125.

10. Gleicher N. Medicina Clínica en Obstetricia. Editorial Médica Panamericana, Bunos Aires 1989; 938.

11. Everson GT. Gastrointestinal Motility in Pregnancy. Gastro Intes. Clin. North. Am. 1992; 21(4): 751-776.

12. Slater G., Aufses AH. Surgical aspects of pregnancy: Intestinal Obstruction. En: Medical, Surgical, and Gynecologic complications of pregnancy. 3 th ed. Baltimore, Williams \& Wilkins, 1985; 659-660. 